\title{
How to get the most from a gene test
}

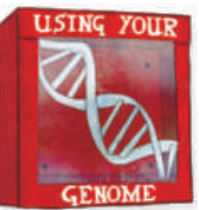

According to two commercial gene-testing services -23 andMe and deCODEme - US Army medic Timothy Richard Gall of Fort Belvoir, Virginia, has a higher-than-average risk of basal cell carcinoma, type 2 diabetes and psoriasis. But much more enlightening than these results, which cost Gall more than $\$ 1,400$, was a free online program called Promethease that he used to further analyse the data. By offering more indepth information and interpreting of more of his genetic variants, Promethease "gives a much more realistic view of the usefulness of the information", Gall says.

Start-ups and services such as Promethease are now developing ways to improve the limited value of information provided by personal genomics companies for consumers and scientists alike.

For instance, Omicia, based in Emeryville, California, is designing software to make sense of entire genome sequences, such as those of the individuals published in this issue (see pages 53 and 60). At present, firms offering genetic testing look only at small variations called single nucleotide polymorphisms, or SNPs. But people looking at their whole genomes will also want to know the meaning of all the different types of variation within them, such as extra copies of genes or flipped sections of DNA. Omicia examines each location in a person's genome and compares it to the company's own analysis of disease risks linked to all the types of variation known to exist." "We've always had the full genome in mind, so for us, any kind of position somebody finds we can link to their genome and to our system," says company co-founder Martin Reese.

Of course, most consumers are still stuck with SNPs, and Promethease attempts to squeeze as much information as possible out of these. The program uses data compiled in a wiki called SNPedia, launched in 2006 and run in the spare time of bioinformatician Mike Cariaso and scientist/entrepeneur Greg Lennon. Their wiki contains information selected from the vast public databases commonly used for research, such as dbSNP, and tries to make it more useful by, for instance, including short

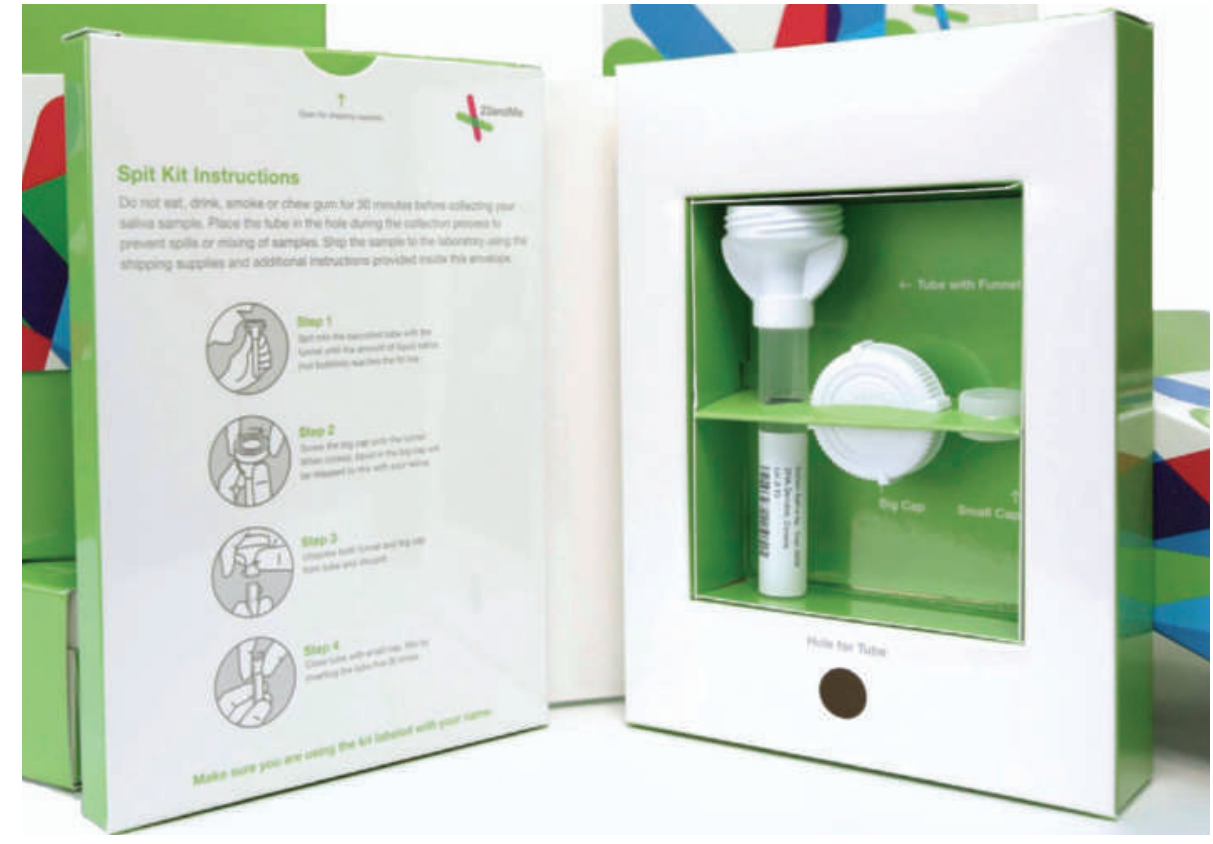

23andMe analyses saliva collected in home test kits (above) for small genetic variations.

written interpretations of the SNPs' importance in various health conditions on the basis of published studies. Compared with reports delivered by gene-testing companies, Promethease reports are more detailed and nuanced containing information on, for example, more SNPs, how common each of a person's particular genetic variants are and the magnitude of the likely impact of each variant.

Cariaso, who lives in Bethesda, Maryland, says that the ability to link genes to traits through SNPedia will become more useful with more individuals' data - so he has begun analysing data from the Personal Genome Project (PGP). This aims to sequence and post the genomes of as many people as possible, along with data about their medical, mental and physical characteristics. PGP released its first batch of data on 21 October, to grumblings about its quality. Two days later, Daniel MacArthur, a postdoc at the Wellcome Trust Sanger Institute in Cambridge, UK, wrote in his blog that the data were "pretty underwhelming", containing mostly low-quality sequence information on just four people that covers only $0.13 \%$ of the entire genome. "Given the hype surrounding this data release I'm a little disappointed by the data itself", he wrote.

George Church, a Harvard University molecular geneticist who runs the PGP, doesn't disagree. "You should be underwhelmed" by the first data release, he says. He calls it "really more of a social engineering event than a true production announcement". Right now, Church says, the main focus is recruiting more study participants to improve the project's scope and its data quality; he adds that 9,500 people have now volunteered.

Already, Church's 'social engineering event' has stirred a public dialogue about the usefulness of linked genetic and medical data. For instance, Gall is one of seven people who have released their Promethease reports publicly on SNPedia independently of any research project.

Gall says he posted his data in part because he knows its value today is still limited, and he wants that to change: "By making it public, I hope that I will only increase its usefulness to me personally,' Gall says. That shouldn't be too hard: Gall notes that his SNPs didn't even reveal the makeup of some medically crucial genes such as those that determine his compatibility for organ donations - whose composition he can learn for free as a member of the military: "In that sense, 23andMe and deCODEme are not worth the price," he says.

Erika Check Hayden 